\title{
Acute Lymphoblastic Leukemia, Classification, Clinical features and Diagnosis
}

\section{Fatimah Kadhim Ibrahim AL- Mahdawi $(\mathrm{PhD})^{1}$ and Mazin Razooqi Mohammed $(\mathrm{FICMS})^{2}$}

\begin{abstract}
Background: Leukemias are classified as lymphoid or myeloid, dependent on the type of stem cell that is affected. In addition, leukemia is classified as chronic or acute. Acute leukemia is a production of bone marrow-derived immature cells (blasts), include solid organs or peripheral blood. The FAB Cooperative Group original classification scheme proposed to divide1 ALL into three subtypes (L1 - L3). Currently, the world health organization (WHO), modify FAB classification depending on immunophenotype. Symptoms presence of anemia, splenomegaly, and thrombocytopenia, and those are naturally present at diagnosis, indicating the degree to which leukemic lymphoblasts have replaced the bone marrow and the first mark to an ALL diagnosis is typically an abnormal complete blood count result.

Objective: To introduce causes of acute lymphocytic leukemia, recent classification methods, diagnosis, and symptoms and diagnosis.

Conclusion: Acute lymphocytic leukemia occurs due to a defect in the bone marrow and is classified into several types. The most important classification by the World Health Organization is depending on immunophenotype. The main symptoms are the increase in white blood cells with anemia and thrombocytopenia.
\end{abstract}

Keywords: Acute Lymphoblastic Leukemia, Blood

Corresponding Author: fatimakad87@yahoo.com

Received: $2^{\text {nd }}$ June 2020

Accepted: $23^{\text {th }}$ August 2020

DOI:https://doi.org/10.26505/DJM.19025390602

\footnotetext{
${ }^{1}$ Medical Lab Technologies Department, Bilad Al-Rafidain University College -Diyala- Iraq

${ }^{2}$ Baqubah Teaching Hospital- Diyala Health Directorate-Diyala-Iraq
}

\section{Introduction}

Abnormal production of blood cells in the bone marrow and blood-forming organs leads to a malignant disease usually referred to as leukemia, which can be categorized according to the rate progression [1]. Leukemia etiology is poorly described, with most authors finding it to be multifactorial. Thus, viral infections (Epstein Barr), ionizing radiation exposure, chromosomal abnormalities (Down syndrome), chemical compounds (benzene), or families with leukemic history/ members constitute the risk factors [2].

\section{Classification}

Leukemia is a class of malignant hematologic disorder with mesenchymal 
(lymphoid or myeloid) origin arising from the bone marrow, produces a high number of abnormal hematopoietic cells in terms of their proliferation, differentiation, and cell death programming (apoptosis) [3]. Leukemias are classified as lymphoid or myeloid, dependent on the type of stem cell that is affected. In addition, leukemia is classified as chronic or acute [4].

\section{Acute Leukemia}

Acute leukemia is a production of bone marrow-derived immature cells (blasts), include solid organs or peripheral blood. Lymphoid leukemia is derived from the lymphoid stem cells, which normally give rise to the lymphocytes (T-cells, B-cells, dendric cells, natural killer cells, and plasma cells) [5]. For several forms of leukemia, the ratio of blast cells essential for acute leukemia diagnosis is greater than twenty percent, and don't need any minimum percentage of blast cell when certain morphological and cytogenetic characteristics are present [6].

\section{Types of Acute Leukemia}

Acute leukemia is divided into two main types acute lymphoblastic leukemia and acute myeloid leukemia dependent on the origin of whether the blasts are present to be lymphoblasts or myeloblasts [7].

\section{Acute Lymphoblastic Leukemia (ALL)}

Acute lymphoblastic leukemia. "Acute" means leukemia will develop rapidly and will be lethal within a few months if untreated. "Lymphoblastic" means that it develops from early immature forms of lymphocytes, a type of leukocytes [8].

\section{Classification of ALL}

The classification of ALL by FrenchAmerican-British is based on morphology and cytochemical staining of blasts [9] Figure (1). The FAB Cooperative Group original classification scheme proposed to divide1 ALL into three subtypes (L1 - L3) [10]. Table 1 explains the characteristics of three subgroups of ALL as reported by Conter et al., 2004 [11].

Table (1): Characteristics of Acute Lymphoblastic Leukemia

\begin{tabular}{|c|ll|}
\hline Subtypes of ALL & \multicolumn{1}{|c|}{ Characteristics } \\
\hline L1 lymphoblast & $\bullet$ & $\begin{array}{l}\text { The small cells with a high nucleus-to-cytoplasm ratio. } \\
\text { - }\end{array}$ \\
& $\begin{array}{l}\text { Pale blue cytoplasm is rare, and confined to a tiny portion of the perimeter. } \\
\text { The cells have unclear nuclei and membranes of nuclei vary from round to } \\
\text { cleft. }\end{array}$ \\
\hline L2 lymphoblast & $\bullet \begin{array}{l}\text { Larger cells with a lower nucleus-to-cytoplasm } \\
\text { ratio, particularly in a more heterogeneous population } \\
\text { Prominent nuclei (often with perinuclear chromatin condensation) and } \\
\text { membranes of nuclear may be irregular or reniform. }\end{array}$ \\
\hline L3 lymphoblast & $\bullet \begin{array}{l}\text { Heterogeneous group of cells similar to Burkitt's-like leukemia, with deep } \\
\text { basophilic cytoplasm and prominent cytoplasmic vacuolization }\end{array}$ \\
\hline
\end{tabular}




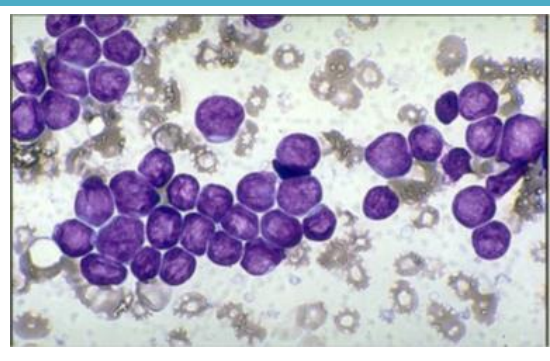

A

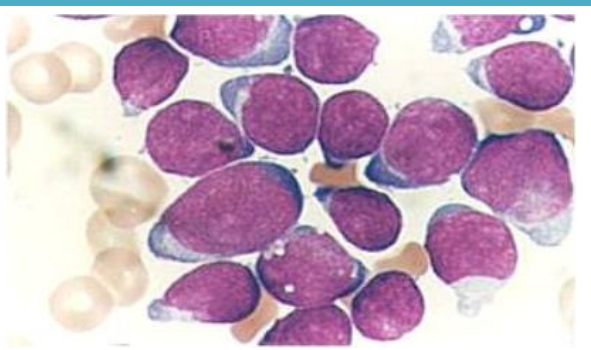

B

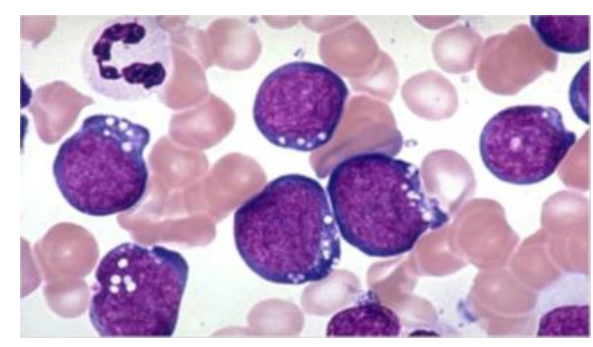

C

Figure (1): FAB morphological classification of lymphoblasts

A: L1, B:L2, and C: L3 lymphoblasts [12]

Currently, the World Health Organization (WHO), modify FAB classification depending on immunophenotype as follows: [13].

- Acute Lymphoblastic Leukemia in B-cell

- Early pre-B Acute Lymphoblastic Leukemia (named pro B Acute Lymphoblastic Leukemia) - around 10\% of cases.

- Common Acute Lymphoblastic Leukemia around $50 \%$ of cases. - Mature B-cell Acute Lymphoblastic Leukemia (Burkitt's leukemia) - around $4 \%$ of cases.

- Acute Lymphoblastic Leukemia in T-cell.

- Pre-T Acute Lymphoblastic Leukemia around $5-10 \%$ of cases.

- Mature-T cell Acute Lymphoblastic Leukemia - around 15-20\% of cases.

Recent years have seen tremendous progress in uncovering genetic lesions that influence the biology of ALL. In recognition of these advances, 2008 WHO classification incorporated the category of B-lymphoblastic leukemia/lymphoma with recurrent genetic abnormalities into the classification of precursor lymphoid neoplasms. Based on the knowledge available at the time, genetic lesions associated with distinct clinical features, immunophenotype, prognosis, or other unique biological characteristics were included in this category [14].

Immunophenotyping is an important adjunct to diagnosis and is helpful in confirming the diagnosis as well as lineage allocation to leukemia. When interpreting the immunophenotype data, one should keep in mind that no single antigen is specific for any neoplasm and that combining morphologic features and a panel of antigenic markers is necessary to obtain a correct diagnosis Table (1). 
In addition, the combinations of markers expressed are to some extent reflective of the normal B- and T-cell development and can be used to determine the stage of development at which the leukemia transformation happened Table (2). In B-ALL this stage of maturation frequently correlates with the underlying cytogenetic abnormality. In $\mathrm{T}$ ALL, the stage of maturation has been shown to correlate with survival in some studies. Finally, it must be pointed out that the expression of myeloid antigens is seen frequently in B- and T-ALL and does not preclude the diagnosis of ALL. Similarly, Blineage antigens can be expressed in T-ALL and vice versa. The criteria for making the diagnosis of acute leukemias of ambiguous lineage have been extensively revised in the 2008 World Health Organization (WHO) classification. The requirements for assigning more than 1 lineage to given leukemia are summarized in Table (3).

Table (2): Prevalence of migraine among obese versus non-obese individuals

\begin{tabular}{|c|c|}
\hline Commonly positive & Variable expression \\
\hline $\begin{array}{l}\text { B-ALL } 19 * \\
\text { cCD22* } \\
\text { cCD79a* } \\
\text { PAX5† } \\
\text { CD10 } \\
\text { sCD22 } \\
\text { CD24 } \\
\text { TdT }\end{array}$ & $\begin{array}{l}\text { CD20 } \\
\text { CD34 } \\
\text { CD45 } \\
\text { CD13 } \\
\text { CD33 } \\
\text { sIgM }+\end{array}$ \\
\hline $\begin{array}{cc}\text { T-ALL } & \mathrm{cCD} 3 \S \\
& \mathrm{TdT} \\
\text { CD7 }\end{array}$ & $\begin{array}{c}\text { CD1a } \\
\text { CD2 } \\
\text { sCD3 } \\
\text { CD4I } \\
\text { CD5 } \\
\text { CD8I } \\
\text { CD10 } \\
\text { CD34 } \\
\text { CD99 } \\
\text { CD19 } \\
\text { CD33 } \\
\text { CD79a } \\
\text { CD117 } \\
\text { CD56 }\end{array}$ \\
\hline \multicolumn{2}{|c|}{ 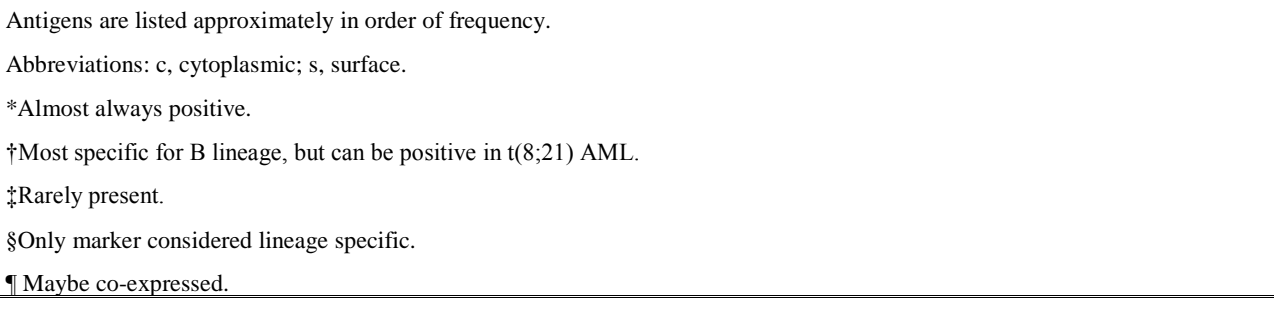 } \\
\hline
\end{tabular}


Table (3): Immunophenotype of B and T lymphocyte progenitors

\begin{tabular}{|c|c|c|c|c|c|c|c|}
\hline \multicolumn{2}{|c|}{ B lineage } & CD10 & CD19 & $\mathrm{CD} 22$ & CD79a & Tdt & $\mathrm{Ig}$ \\
\hline \multirow{2}{*}{\multicolumn{2}{|c|}{$\begin{array}{l}\text { Early precursor (pro-B) } \\
\text { Intermediate (common) }\end{array}$}} & - & + & + & + & + & - \\
\hline & & + & + & + & + & + & - \\
\hline \multicolumn{2}{|c|}{ Pre-B } & \pm & + & + & + & + & C-mu \\
\hline $\mathrm{T}$ lineage & CD1a & CD2 & CD3 & CD4 & CD7 & CD8 & CD34 \\
\hline Pro-T & - & $\begin{array}{lll}- & - \\
-1\end{array}$ & $\mathrm{C}$ & - & + & - & \pm \\
\hline Pre-T & - & + & $\mathrm{C}$ & - & + & - & \pm \\
\hline Cortical T & + & + & $\mathrm{C}$ & + & + & + & - \\
\hline Medullary T & - & + & $\mathrm{C}, \mathrm{S}$ & $*$ & & $*$ & - \\
\hline
\end{tabular}

Table (4): Criteria for Ambiguous Lineage Assignment

\begin{tabular}{|c|c|}
\hline Lineage & Markers \\
\hline Myeloid & $\begin{array}{l}\text { Myeloperoxidase staining or At least } 2 \text { markers of monocytic differentiation } \\
\text { - NSE } \\
\text { - CD11c } \\
\text { - CD14 } \\
\text { - CD64 } \\
\text { - Lysozyme }\end{array}$ \\
\hline T lymphocyte & $\begin{array}{l}\text { Cytoplasmic CD3 demonstrated by flow cytometry using antibody specific to the epsilon } \\
\text { chain } \\
\text { - Surface CD3 }\end{array}$ \\
\hline B lymphocyte & $\begin{array}{l}\text { Strong CD19 with at least } 1 \text { additional marker or Weak CD19 with at least } 2 \text { additional } \\
\text { markers } \\
\text { - CD79a } \\
\text { - Cytoplasmic CD22 } \\
- \text { CD10 }\end{array}$ \\
\hline
\end{tabular}

\section{Clinical features of $\mathrm{ALL}$}

Symptoms and signs of acute leukemia are caused by blasts cells infiltrating the bone marrow or extramedullary [10]. The signs are anemia, splenomegaly, and thrombocytopenia [1]. Others common symptoms and signs include fever, fatigue, weight loss, loss of appetite, malaise, palpitations, shortness of breath, dizziness, cold sensitivity, paleness, bleeding and easy bruising, sore throat, problems in vision, pain in joints, nausea, night sweats, heaabdominal abdominal discomfort, Feeling of fullness in the abdomen [15].

\section{Diagnosis of ALL}

Abnormal leukocyte, thrombocytopenia and anemia are naturally present at diagnosis, indicating the degree to which leukemic lymphoblasts have replaced the bone marrow [16]. The first mark to an ALL diagnosis is typically an abnormal complete blood count result. A raised leukocyte (WBC count more than $10.000 / \mathrm{mm} 3$ ) [12]. Peripheral blood smears show blasts cells. Present thrombocytopenia (platelet count less than $100.000 / \mathrm{mm} 3$ ), and also anemia is present (hemoglobin less than $10 \mathrm{~g} / \mathrm{dL}$ ), which is typically normocytic and normochromic with decrease reticulocytes number[17].

\section{Conclusions}

Acute lymphocytic leukemia occurs due to a defect in the bone marrow and is classified into several types. The most important classification by the World Health 
Organization is depending on immunophenotype. The main symptoms are the increase in white blood cells with anemia and thrombocytopenia.

\section{Recommendations}

For classification of acute leukemia, it's better to involve many parameters including morphology and immunophenotyping markers.

\section{References}

[1] M. Roy, A. Mukherjee, S. Mukherjee, and J. Biswas, "Leukemia Causes, Symptoms \& Treatment.

[2] P. Stana, G. Marina, and D. Anca, "Oral Manifestations in Acute Leukemia as the First Sign; The Interdisciplinary Approach of Diagnosis and Treatment," J Mind Med. Sci 2015; 2(2):186-192.

[3]P. Chandran et al., "Mesenchymal stromal cells from patients with acute myeloid leukemia have altered capacity to expand differentiated. hematopoietic progenitors," Leuk. Res., vol. 39, no. 4, pp. 486-493, 2015. [4] W. Lockwood, "Leukemia: AML, CML, ALL and CLL." 2015.

[5]N. J. Goulden and C. G. Steward, Pediatric Hematology: Methods and Protocols, vol. 91. Springer Science \& Business Media, 2004.

[6]M. Antica, Acute Leukemia: The Scientist's Perspective and Challenge. BoDBooks on Demand, 2011.

[7]A. V. Hoffbrand and D. P. Steensma, Hoffbrand's essential haematology. John Wiley \& Sons, 2019.

[8]R. Hoffman, E. J. Benz Jr, L. E. Silberstein, H. Heslop, J. Anastasi, and J. Weitz, Hematology: basic principles and practice. Elsevier Health Sciences, 2013.
[9]N. L. Harris et al., "The World Health Organization classification of hematological malignancies report of the clinical advisory committee meeting, Airlie House, Virginia, November 1997," Mod. Pathol., vol. 13, no. 2, p. 193, 2000.

[10] P. Mittal and K. R. Meehan, "The acute leukemias," Hosp. Physician, vol. 5, pp. 37 44, 2001.

[11] V. Conter and C. Rizzari, "S Sala A," Chiesa R, Citterio M ala Biondi A Ab Acute Lymphoblastic Leuk. Orphanet Encycl. Creat. date December, 2004.

[12]J. Roganovic, "Acute lymphoblastic leukemia in children," in Leukemia, IntechOpen, 2013.

[13]S. Mostert, M. N. Sitaresmi, C. M. Gundy, and A. J. P. Veerman, "Influence of socioeconomic status on childhood acute lymphoblastic leukemia treatment in Indonesia," Pediatrics, vol. 118, no. 6, pp. e1600-e1606, 2006.

[14]S. McGregor, J. McNeer, and S. Gurbuxani, "Beyond the 2008 World Health Organization classification: the role of the hematopathology laboratory in the diagnosis and management of acute lymphoblastic leukemia," in Seminars in diagnostic pathology, 2012, vol. 29, no. 1, pp. 2-11.

[15] E. A. Shephard, R. D. Neal, P. W. Rose, F. M. Walter, and W. Hamilton, "Symptoms of adult chronic and acute leukaemia before diagnosis: large primary care case-control studies using electronic records," $\mathrm{Br} \mathrm{J}$ Gen Pr., vol. 66, no. 644, pp. e182-e188, 2016. [16]G. Abdul-Hamid, "Classification of Acute Leukemia," in Acute Leukemia-The Scientist's Perspective and Challenge, IntechOpen, 2011. 


\section{[17]C.-H. Pui, Acute lymphoblastic}

leukemia. Springer, 2011.

[18]Stewart WF, Roy J, Lipton RB. Migraine

prevalence, socioeconomic status, and social

causation. Neurology. 2013;81(11):948-55. 